\title{
TÉCNICA E LIBERDADE: MARTIN HEIDEGGER E EUGEN FINK SOBRE O PROBLEMA E A ESSÊNCIA DA TÉCNICA MODERNA GIOVANNI JAN GIUBILATO ${ }^{1}$
}

RESUMO: A filosofia da técnica representa uma dentre as áreas de estudo mais atuais, além de constituir ainda uma disciplina do pensamento filosófico cuja importância se revela cada vez maior no âmbito acadêmico contemporâneo. O presente trabalho tem a intenção de, num primeiro momento, alcançar uma rigorosa fundamentação conceitual da reflexão filosófica de Heidegger e Fink sobre o fenômeno da técnica e as questões relacionadas à sua essência, que incluem a liberdade e o papel da subjetividade. Essa primeira etapa pretende fornecer os pressupostos teóricos para uma discussão que considera não apenas a reformulação do conceito de "técnica" mas se detém sobre as consequências filosóficas dessa recolocação do problema. No contexto da filosofia finkeana, a questão da técnica adquire importância central não apenas para uma compreensão da filosofia como pedagogia, mas igualmente para uma determinação do filosofar numa perspectiva cosmológica, e como dialética (necessária) entre fenomenologia e ontologia.

PALAVRAS-CHAVE: Heidegger, Fink, filosofia da técnica, liberdade, meôntica.

\begin{abstract}
The philosophy of technology represents one of the most current areas of study, as well as it is a philosophical discipline whose importance is increasingly revealed in the contemporary academic context. The present paper firstly intends to present the rigorous conceptual foundation of Martin Heidegger's and Eugen Fink's philosophical reflection on the phenomenon of technology and the questions related to its essence, which include freedom and the role of modern subjectivity. This first step intends to provide the theoretical presuppositions for a discussion that considers not only the reformulation of the concept "technology" but dwells on the philosophical consequences of this replacement of the problem. Particularly in the context of Fink's philosophy, which demonstrates a constant debate with Heidegger's positions, the question of technique acquires a central importance not only for an understanding of philosophy as pedagogy but also for a new determination of philosophy itself in a cosmological perspective.
\end{abstract}

KEYWORDS: Heidegger, Fink, Philosophy of Technology, Freedom, Meontic.

\section{Status Quaestionis}

\footnotetext{
1 Doutor em filosofia pela Bergische Universität Wuppertal, Alemanha. Bolsista Pós-Doc PNPD-CAPES, Programa de Pós-Graduação em Filosofia pela Universidade Estadual de Londrina (UEL). E-mail: giovannijangiubilato@hotmail.com.
} 
A incidência do pensamento de Heidegger na filosofia contemporânea é notória. Depois da publicação dos primeiros quatro volumes dos assim chamados Cadernos Negros (HEIDEGGER, 2014a; 2014b; 2014c; 2015) o filósofo de Messkirch continua ocupando o centro do debate atual. Eugen Fink, ao contrário, é ainda relativamente pouco conhecido. No entanto, seu pertencimento ao mais significativo âmbito da fenomenologia alemã não foi meramente biográfico, embora seu pensamento ainda se situe à sombra dos dois grandes nomes da fenomenologia de Freiburg, Edmund Husserl e Martin Heidegger. Por outro lado, seu pensamento se movimenta de modo único em termos de "proximidade e distância" diante das filosofias de ambos. E mesmo a recepção do pensamento finkeano, que vem gradualmente se consolidado a partir dos anos 90, concentra-se ainda quase exclusivamente sobre sua vinculação com a fenomenologia da consciência transcendental (Cf. LUFT, 2002). Uma rápida consideração da fillosofia de Eugen Fink, elaborada sobretudo ao longo dos numerosos manuscritos referentes aos seus seminários, não é, todavia, suficiente para evitar que tomemos parte em seu profundo enfrentamento com a perspectiva ontológica de Heidegger. Por muito tempo Fink foi considerado ou como o intérprete especializado da fenomenologia de Husserl ou como o filósofo à sombra do pensamento e da grandeza de Heidegger. Entretanto, ambas as interpretações têm um alcance elucidativo demasiado curto, como evidenciam os mais recentes e exemplares estudos e pesquisas sobre o trabalho intelectual conjunto entre Husserl e Fink. A autonomia intelectual e filosófica do ainda jovem Fink diante das filosofias de Husserl e Heidegger é apresentada da seguinte forma:

Fink se esforçava em conceber um modo pelo qual a diferença básica que separava Husserl e Heidegger aos seus próprios olhos poderia ser conectada em uma via dramaticamente convergente [...] ao direcionar a questão que jaz no núcleo da diferença entre Husserl e Heidegger a fim de, aí, encontrar os meios para se mover mais além das conquistas de ambos. [...] Fink se vê compelido a considerar "uma nova e terceira solução" (BRUZINA, 2004, p. 43).

Nessa passagem, Bruzina refere-se claramente, como já o fizera Sepp (2006, p.159) em um estudo precedente, a uma "terceira solução" oferecida pela obra de Fink, o que nos autoriza a caracterizar o seu pensamento não apenas como autônomo, mas igualmente capaz de abranger e combinar as diferentes perspectivas de Husserl e Heidegger. À sua perspectiva filosófica Fink referia-se como "Meôntica", ou ainda "Integração meôntica". Com ela, o mais jovem filósofo da assim chamada "escola de Freiburg" produzia uma inovadora reinterpretação das teorias dos seus mestres colocando a questão da liberdade no centro da tradição fenomenológica, até transforma-a numa verdadeira filosofia da liberdade e da libertação (GIUBILATO, 2017). Disso se depreende que, por um lado, a obra de Husserl constitui o pressuposto necessário e o ponto de partida filosófico mas que, por outro, foi a 
obra de Heidegger que se prestou como constante e decisiva prova de fogo à consolidação de sua filosofia, numa influência que se estendeu ao longo de anos em um enfrentamento tanto profundo quanto profícuo. Diferentemente de Heidegger, que viu na posição egológicotranscendental de Husserl um beco sem saída filosófico, a egologia transcendental husserliana representou também para Fink uma "abstração", todavia uma abstração "necessária, e não somente possível" (FINK, 2006, p.221). Essa insofismável diferença na formulação da questão filosófica entre a abordagem de Heidegger e a fenomenologia de Husserl, que pode ser claramente reconhecida já em Ser e Tempo, não impediu Fink de reconhecer "na Egologia, na ciência transcendental do $\mathrm{Eu}$ e daquilo que ao eu pertence de modo essencial" (i.e., no sistema de correlação a priori de mundo e subjetividade), a única irrupção possível do "sentido existencial da filosofia" (FINK, 2006, p.222). Essa irrupção seria sempre um ato "a cada vez meu" [je-meiniger] da "filosofia enquanto liberação [Befreiung], enquanto ação do singular" (FINK, 2006, p.222). Quanto a isso, podemos concordar com R. Cristin quando ele afirma que a abordagem egológica é tão somente "o solo concreto para a legítima demonstração do conhecimento básico da fenomenologia" (CRISTIN, 2012, p.50), apesar do fato de que, para ele, a essa egologia transcendental da vida da consciência compete uma necessária provisoriedade, uma incompletude filosófica no que diz respeito ao problema da totalidade da intersubjetividade e do mundo. Com efeito, a reflexão de Fink assinala um olhar sinóptico sobre as verdades singulares e as ramificações de uma filosofia - seja esta de Heidegger ou de Husserl - que é capaz de apreender a conexão essencial entre elas para além daquilo que lhes é específico e distinto.

É na primeira fase do pensamento finkeano, temporalmente delimitada pelo período que vai de sua chegada em 1926 a Freiburg até seu doutoramento pela Universidade de Freiburg após do fim da guerra (1946), que as raízes decisivas de sua filosofia podem ser encontradas. Mesmo se, depois da Segunda Guerra Mundial, a filosofia de Fink tomou direções muito distintas e chegou mesmo a adotar uma posição contrária à filosofia transcendental de Husserl e a ontologia de Heidegger, o filosofar compartilhado

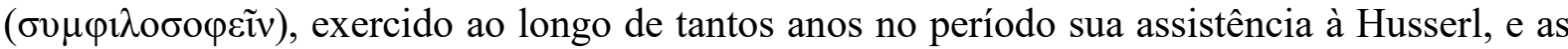
solicitações do pensamento heideggeriano permaneceram invariavelmente determinantes, principalmente no modo de lidar com problemas fundamentais a partir de uma perspectiva de história das ideias. Nesse sentido, sua precursora e nada convencional tese de doutorado de 1929, intitulada Presentificação e Imagem. Contribuições a uma fenomenologia da irrealidade (FINK, 1966, 1-78), os três seguintes estudos sobre a fenomenologia (FINK, 
1966, 79-232), publicados entre os anos de 1930 e 1939 e, ainda, os volumosos materiais que se enquadram no contexto da revisão das Meditações Cartesianas de Husserl e, a ela correlativa, da própria VI. Meditação Cartesiana (FINK, 1989a; 1988b), comprovam a riqueza do desenvolvimento ulterior das filosofias de Husserl e Heidegger por meio de críticas, alterações e de um incansável pensar-além. Este constante movimento de superação e repensamento sobretudo das posições heideggerianas mostra-se de uma forma paradigmática com o seminário inaugural de Fink, datado de 26 de julho de 1946 e proferido na Universidade de Freiburg. O seminário foi intitulado $O$ pressuposto da filosofia e, com ele, Fink assumiu expressamente a continuidade da tradição fenomenológica sob um ponto de vista notoriamente crítico e independente. ${ }^{2}$ Isso é salientado claramente também por G. van Kerckhoven em seu estudo sobre a VI. Meditação Cartesiana e sua diligência. Um exemplo desse filosofar compartilhado de Husserl e Fink revelar-se-ia "no modo como a continuidade da fenomenologia de Husserl somente se tornou viável, para uma geração posterior, sob profundas transformações de seus pressupostos operativos implícitos" (VAN KERCKHOVEN, 2003, p.16). Para uma continuidade todavia crítica e autônoma da tradição fenomenológica, a fenomenologia enquanto tal teve que se transformar no próprio problema a ser investigado, como se pode ver claramente no artigo que Fink escreveu no 1939 sobre $O$ problema da fenomenologia de Husserl (FINK, 1966, 179-223). Um texto posterior, no qual Fink, porém, ainda persiste na intenção de confrontar "motivos fenomenológicos de Husserl e Heidegger" com seu horizonte próprio de problemas filosóficos é o texto referente ao seminário proferido na Universidade de Freiburg no semestre de inverno dos anos 1955/56 sobre Ser, verdade, mundo, o qual recebeu o tão significativo subtítulo "pré-questões ao problema do conceito de fenômeno" (FINK, 1958).

Pode-se dizer que, depois da Segunda Guerra Mundial (a partir de 1946 com sua habilitação e assunção da cátedra em Freiburg), tem início uma segunda fase mais madura do pensamento de Fink, em cujo centro encontra-se a educação como o fenômeno mais fundamental da vida. Em torno dela orbita ainda o conjunto mais geral de sua filosofia tardia. Para Fink, filosofia é já pedagogia ou, dito de outro modo, sua essência é desde o início “doutrina de vida”, i.e., paideia. Tal compreensão foi, evidentemente, amadurecida no diálogo visceral que ele estabeleceu com Sócrates, Platão e Aristoteles, como comprovam seus inúmeros escritos dos anos de 1970. Sua filosofia da educação ou, melhor dito, sua filosofia como educação, está expressis verbis para além do pensamento caracterizado por uma divisão

2 Refiro-me aqui a um documento não publicado e disponível nos Arquivos Eugen Fink da Universidade de Freiburg sob a assinatura E15/136. 
do trabalho "das organizações trabalhistas modernas", as quais corrompem "a ideia da educação" e seu verdadeiro ideal (FINK, 1992, p.13). O propósito de Fink, no entanto, é igualmente anterior a toda forma possível de práxis pedagógica, pois ele tem em vista uma meditação prévia [Vorbesinnung] sobre as perguntas fundamentais da educação, voltada "para uma teoria futura da pedagogia que compreenda a humanidade como a essência do mundo" (FINK, 1992, 196). Para essa meditação prévia sobre os modos de ser da educação enquanto uma obviedade da existência humana [Dasein] e sobre o "ser-aí" existente no âmbito duplo da natureza em nós e da liberdade, a interpretação da conexão entre natureza, liberdade e mundo (técnico) é decisiva. Até que ponto essa reflexão orientada a uma filosofia da educação intenciona uma pedagogia como filosofia primeira, cujos elementos fundamentais são a autoconsciência ainda não tornada a si mesma e a liberdade ainda oculta a essa consciência, foi claramente exposto por Trawny (2005) em um artigo sobre a "doutrina da vida" de Fink. O ser humano deve, portanto, lançar sempre de novo sua liberdade a fim de realizá-la. Esse se lançar de uma possibilidade interior em direção à liberdade se equivale à essência do legítimo pensamento fundamental da fenomenologia, o que nos liberta da "atitude natural" e nos permite superar suas limitações, graças ao ato de libertação da redução fenomenológica. Finalmente podemos dizer que Fink, dentro da estrutura fenomenológico-transcendental da filosofia husserliana - ao contrário de Heidegger, que desde o princípio rompe notavelmente com ela - mostra como a vida humana pode ser pensada como um movimento articulado e dialético de libertação no sentido do exercício livre do filosofar e da própria liberdade.

Para Fink, a liberdade designa fundamentalmente a relação entre a origem absoluta e o engendramento do que é constituído, ou seja, entre o constituinte e o constituído, o qual solapa o campo de atuação correlativo entre subjetividade e mundo. Nisso se evidencia ainda a forte influência da dicotomia determinante na fenomenologia husserliana entre transcendental e mundano. Esta dicotomia, contudo, não ressurge em Fink não sob uma concepção "horizontal" como em Husserl mas, antes, vertical. Decisivos nesse contexto são os dois conceitos de $\tilde{\varepsilon} \kappa \beta \alpha \sigma \iota \varsigma$ e $\kappa \alpha \tau \alpha ́ \beta \alpha \sigma \iota \varsigma$, retomados da neoplatônica que remete a Plotino e introduzidos por Fink na estrutura de sua "fenomenologia meôntica". Em uma de suas mais recentes publicações Trawny ressaltou o vínculo essencial entre a dimensão daquela outra liberdade tornada impossível na dimensão concreta do mundo e o caráter transformativo da filosofia. Sob essa ótica, a filosofia seria uma "metamorfose radical, i.e., violenta [...] do humano indiferenciado e normalizado ao qual se impõe o pensar" (TRAWNY, 2015, p.157). A liberdade filosófica apresenta-se, portanto, como uma impossibilidade, uma vez que ela é 
liberdade diante de todas as possibilidades mundanas. Perante uma tal impossibilidade, o sujeito é notavelmente "desintegrado" (ou des-humanizado, para usar uma expressão de Fink) e, somente desta forma, finalmente libertado. Tal seria a "alternativa neoplatônica" (TRAWNY, 2015, p.160) que o mesmo Fink parece conceber com a sua filosofia meôntica da libertação e, especificamente, com a sua teoria da redução fenomenológica. De fato, segundo as palavras de Fink, a redução não é meramente um "método que pode ser uma vez aprendido, mas é a própria tarefa da filosofia na medida em que seu telos é a liberdade humana" (FINK, 2006, p.222).

O drama da Segunda Guerra Mundial representou, também para Fink, uma dolorosa ruptura, o que não quer dizer que houve, por isso, uma cesura insuperável entre a reflexão orientada a uma filosofia da educação, característica da assim designada segunda fase e o período do projeto fenomenológico junto a Husserl, característica da primeira fase do pensamento de Fink. Ao contrário, o que parece se estabelecer não é senão uma continuidade entre as reflexões anteriores e posteriores à Guerra. Nesse sentido, a preparação da edição das obras completas de Eugen Fink, organizada por H. R. Sepp e C. Nielsen em comum acordo com F. A. Schwarz, o último assistente de Fink, e a família Fink no verão de 2004, foi não apenas um fato que fez jus à riqueza de seu pensamento como também à criação indispensável de um instrumento filosófico-filológico de fomento à pesquisa especializada. A empreitada responde ainda à necessidade filosófica de rastrear o desenvolvimento histórico desse pensamento, tanto em seu aspecto mais geral quanto em suas ramificações. Importantes razões desse andamento editorial se encontram no fato de que, por um lado, quase todas as obras publicadas pelo próprio Fink em vida se encontram esgotadas e, assim, sua reedição seria de todo modo digna de ponderação e, por outro, na relevância da publicação dos numerosos materiais inéditos. O objetivo dessa tarefa seria, sob o sustentáculo da publicação da parte inédita de sua obra, oferecer aos pesquisadores a possibilidade de dispor do conjunto de toda sua obra segundo um princípio de apresentação coerente. Além disso, é nessas numerosas anotações que Fink indica, com toda abertura e franqueza, os limites dos conceitos filosóficos de Husserl e Heidegger - assim é, por exemplo, no contexto de seu Escrito de diferenciação, por meio do qual "as posições tanto de Husserl quanto de Heidegger deveriam ser criticamente esquadrinhadas" (GIUBILATO, 2014, 320). Desse modo Fink conseguiu magistralmente perfilar sua posição filosófica própria e autônoma. 


\section{A questão da técnica}

O mundo da vida moderno é marcado pela consumação da técnica, sem a qual a vida tal como a conhecemos, via de regra, não se deixaria mais organizar. A presença sempre mais manifesta e indispensável da técnica nos procedimentos mais elementares da prossecução da vida humana, tornou-se, sem dúvida, um problema filosófico de primeira classe. Em meio ao movimento filosófico da Escola de Freiburg, foi principalmente Eugen Fink (1905-1975) que, junto com Heidegger, manteve-se durante toda sua vida no rastro desse fenômeno. De fato, entre outras coisas, Fink era membro ativo do grupo de estudo "Homem e técnica" da Associação dos engenheiros alemães. Mas, esta é a nossa hipótese hermenêutica de fundo, a filosofia da técnica de Fink só pode ser adequadamente determinada em seu teor filosófico sobre o pano de fundo da análise da técnica realizada por Heidegger, e em contraposição a ela.

\section{II.1 Heidegger}

A partir de uma crítica explicita à fenomenologia husserliana e à sua disposição metódica de base, juntamente com uma crítica igualmente violenta à tradição do pensamento ocidental como um todo, tipificada como tradição exclusivamente teoreticista, o grande e indiscutível mérito de Heidegger é o de ter pensado a condição humana para além de qualquer garantia de transcendência - seja esta religiosa ou até mesmo cientifica - e de ter trazido o problema da existência, em sua radical finitude, para o centro do palco filosófico da contemporaneidade. Ainda que nos últimos anos o debate em torno do pensamento de Heidegger tenha sido quase totalmente dominado pelas temáticas dos Cadernos Negros e das ali expressas posições antissemitas, o filósofo francês Jean-Luc Nancy, ao menos em duas ocasiões, chamou a atenção para o fato de que a grandeza do pensamento de Heidegger reside justamente nos conceitos de Existenz e Endlichkeit (NANCY, 2014, p.103; 2015, p.47).

Apagadas todas as luzes da transcendência, dos valores absolutos e das verdades perenes, colapsadas todas as garantias onto-teológicas da tradição, todos os valores universais da antropologia humanista e seus grandes pilares conceituais - da tradição grega antiga bem como da judaico-cristã - a existência é pensada em sua radical finitude enquanto Dasein. Este conceito indica a modalidade originária do movimento da vida humana anterior a qualquer atitude teorética de pura especulação diante do mundo. Justamente ao final de um percurso de intensa elaboração filosófica (1919-1926) o qual significou ao mesmo tempo uma ruptura 
com o horizonte teoreticista tradicional e sua consequente reificação da vida humana como uma mera coisa dentre outras coisas, Heidegger apresenta, em Ser e Tempo, o modo de ser

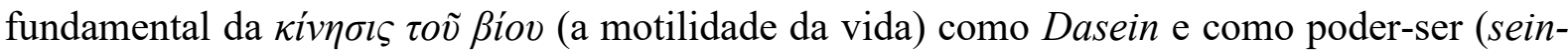
können).

O processo de desconstrução [Abbau] e de desmontagem dos conceitos herdados acriticamente pela tradição metafísica, motivado pela necessidade de alcançar uma compreensão originaria do fenômeno da vida, dirige-se fundamentalmente às duas raízes principais do pensamento ocidental: por um lado, a concepção grega antiga que deriva da definição do humano como "animal político, dotado de razão e linguagem”, formulada por

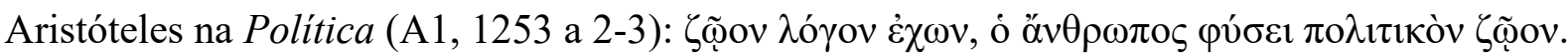
Por outro, a concepção bíblica segundo a qual o humano é "pessoa" e por isso dotado de pensamento e vontade, i.e., capaz de entender e querer, uma vez "criado à imagem e semelhança de Deus" (Gên. I, 26). O confronto heideggeriano com os fundamentos da antropologia humanística recusa o confinamento da essência do ser humano nos limites lógicos da definição de gênero mais diferença específica, e busca apreender o sentido originário da motilidade da vida humana enquanto abertura e possibilidade. De fato, já na literatura humanística acerca da dignitas hominis (dignidade humana), a celebração do humano contra a tradição medieval do contemptus mundi (fuga e desprezo pelo mundo, atitude espiritual típica da religião cristã) não está associada a uma determinação fixa e imóvel de sua natureza mas, antes, à constatação de que o humano é um animal "não definido". Enquanto os demais seres vivos estão "aprisionados" em uma essência pré-definida e predeterminada, o humano é suis ipsus plastes y fictor, ou seja, é aquele "que se faz e fabrica a si mesmo" e deve, portanto, encontrar sua essência em sua própria existência, deve dar-se a si mesmo. Mais tarde será a vez de Kant denunciar a insuficiência da definição grega do humano como animal racional. Em sua obra $A$ religião nos limites da mera razão (1793), ele se pergunta pelo que constitui a humanitas (a humanidade) própria ao humano e adianta que nem a animalitas nem a rationalitas oferecem, sozinhas, uma resposta satisfatória. Faz-se aqui necessário, segundo Kant, a convocação do que ele chama de spiritualitas ou personalitas, o que ele explicita em termos filosóficos como o fato de que o ser humano é, em si mesmo, sempre um fim e nunca um meio, nunca um instrumento para uma conquista ulterior - ideia esta que remete, mesmo que indiretamente, à raiz bíblico cristã. Este último refúgio da natureza humana erigido pelo Esclarecimento, no entanto, vem sendo desmoronado na contemporaneidade e o humano, como afirma Nietzsche em um fragmento da primavera de 
1884, reconhece-se como "animal ainda não definido" - das noch nicht festgestellte Tier (NIETZSCHE, 1954, p. 621). Tais palavras marcam simbolicamente o encerramento do século XIX e início do século XX na história do pensamento.

Heidegger se confronta e responde a estas questões - as quais, segundo sua perspectiva, poderiam ser reunidas sob a guarida da "questão tradicional da filosofia" reconduzindo o pensamento ao problema do ser no intuito de enfrentá-las a partir de uma perspectiva inteiramente nova, qual seja, a partir de uma análise da vida humana, de seu movimento e de sua dinâmica particular, mas também de sua característica capacidade de se modificar e de se adaptar às condições de seu estar no mundo de maneira a tornar possível uma orientação crítica do próprio movimento da vida e da existência. A análise da existência que Heidegger apresenta em Ser e Tempo como seu modo alternativo de abordar a questão do ser e do sentido do ser é basicamente uma análise que, nascendo da própria experiência do humano no mundo por ele habitado, retorna à existência a fim de orientá-la e conduzi-la à sua realização, ao seu desdobramento apropriado, à sua forma completa e acabada. Heidegger concebe a existência humana como uma obra de arte à qual a justa orientação pretende conferir uma bela forma, uma forma apropriada à sua natureza. A partir disso se compreende que o status de Ser e Tempo em nada condiz com o de uma teoria meramente abstrata que perdeu seus legames com a dimensão prática da existência humana mas, ao contrário, com o de uma verdadeira "filosofia prática", a qual surge da vida e volta-se à vida para realizá-la.

Dessa forma, a articulação conceitual da facticidade da vida, irredutível às operações intencionais da consciência, junta-se à criação de um léxico virgem - i.e., não contaminado pelas camadas de sentido da metafísica tradicional - a fim de revelar a dimensão prática de abertura e liberdade que caracteriza a essência da existência finita. Isso comporta tanto um abandono da teoria tradicional da autoconsciência, que encontrara seu limite na fenomenologia husserliana, quanto a inauguração de um domínio original do pensamento, no qual se fundamenta a possibilidade de que a vida humana se desprenda de sua dinâmica arruinante de degradação [Ruinanz, Verfall], de encobrimento [Verdeckung] e de precipitação [Sturz] para alcançar uma espécie de autossalvação independente e ancorada em sua própria capacidade de se orientar mesmo diante da obscuridade de uma finitude radical. Esta leitura do magnum opus heideggeriano se inscreve na linha interpretativa que o considera como uma obra de filosofia prática e tem, portanto, a vantagem de enfatizar o movimento da própria libertação - que coincide com sua autossalvação -, de um livre agir inscrito na possibilidade mais característica da existência humana que. 
É sobre esta base teorética e a crítica da metafísica da subjetividade moderna que Heidegger, imediatamente depois da publicação de Ser e Tempo, dirige-se de maneira sempre mais decidida a uma interrogação do avento do mundo da técnica, que mostra se, pouco a pouco, como o destino escondido da metafísica moderna. Com efeito, Heidegger explicitou sua análise da técnica moderna em poucos trabalhos: entre eles, na famosa conferência de 1953 intitulada A questão da técnica. Assim mesmo, como podemos afirmar junto a Seubold, a técnica não foi apenas o tema predileto de Heidegger, mas "o tema de seu pensamento" (SEUBOLD, 1986, p.16) par excellence, aquele que perpassa seus escritos como um fio condutor. A análise do problema da técnica tem início depois da chamada "virada" no quadro do pensamento de Heidegger. Desta feita, não nos é necessário esclarecer a técnica em termos de seu teor antropológico-instrumental para lograr sua determinação filosófica. A relação instrumental meio/fim pertence, na realidade, à técnica e, dessa forma, também o produzir e o fabricar das coisas; a essência da técnica - e a filosofia se ocupa disso - mostra-se de outra maneira.

No ensaio A questão da técnica encontramos a famosa afirmação segundo a qual "a essência da técnica não é algo técnico" (HEIDEGGER, 2000, p.7). O questionamento ontológico, para o qual a técnica é uma modalidade de "desvelamento" [Entbergung] do ser, toma aqui distância tanto de uma perspectiva instrumental - que vê no fenômeno da técnica a generalização da relação meio/fim -, quanto de uma perspectiva antropológica que interpreta a técnica como uma atividade humana. Heidegger afirma que "a técnica é um modo do desvelamento. Se nos atentarmos a ela, então se nos abre um domínio totalmente outro para a essência da técnica. É o domínio do desvelamento, ou seja, do verdadeirar [Wahr-heiten]" (HEIDEGGER, 2000, p.13). Esse desvelamento (ou acontecimento apropriativo) da verdade já se encontra no fundamento da techne grega; ele se aplica, todavia, igualmente à técnica moderna. Na modernidade, o 'desvelamento' da técnica não se desdobra essencialmente como um pro-duzir no sentido antigo-clássico da palavra mas, antes, como uma pro-vocação [Heraus-forderung] da pv́øıৎ que, por sua vez, exige e espera da técnica, com uma imposição destinatária (entendida como Schickung), ser o fundo inesgotável da materialidade manipulável e calculável, objeto de todas as modalidades do produzir, do representar e do ordenar - em suma, do Ge-stell (normalmente traduzido em português como 'dispositivo').

Se o desfecho [Geschick] vale do mesmo modo que o dispositivo, então nisso consiste o maior dos perigos, e este se nos comprova sob duas perspectivas: 1) assim que o desocultado deixa de se referir ao humano como objeto e 2) assim que o humano, dentre os 
desprovidos de objetos, torna-se apenas o requisitante do recurso, então ele chega à beira do salto, justamente ali onde ele próprio deve ser tomado somente como recurso" (HEIDEGGER, 2000, p.27). Essa fundamentalidade ontológica do dispositivo para o desvelamento de humano e mundo não é, entretanto, qualificada apenas de maneira negativa. No desfechar [Zuschicken] do dispositivo abre-se ainda aquilo que, segundo um outro princípio, mantém a salvo o desvelar da verdade do ser. Anuncia-se com isso uma "virada", ainda oculta, mas presentificada em seu ocultamento.

Isso aponta para o significado onto-historial da técnica e, com isso, explicita como o problema da técnica, junto às questões do ser e do humano [Dasein], constituem uma coordenada fundamental do pensamento de Heidegger, o qual, a partir de uma superação da abordagem ainda "transcendental" de Ser e Tempo, passa a ser chamado "pensamento ontohistorial [Seynsgeschichtliches Denken]. Em contraposição a este, como é sabido, o pensamento onto-teológico ocidental se caracteriza pelo "esquecimento do ser", o qual culmina em ambas ciência e técnica (e configura a assim chamada época do "abandono" do ser). Desse modo, o desafio que a técnica coloca ao pensamento se encontra precisamente nesse vacilar entre a salvação e o perigo.

Finalmente se pode dizer que análise da técnica de Heidegger se origina e transita no âmbito do pensamento do Ser e da história do ser. Esse atributo ontológico do seu pensamento erige a camada sobre a qual Fink formula sua própria análise da questão da técnica. Fink, de fato, compartilha com Heidegger a postura - ainda fenomenológica, presente em Ser e Tempo - de se referir aos conceitos da tradição filosófica e, nesse referir-se, executar ao mesmo tempo uma crítica que consiste no desconstruir, no desmontar [Ab-bau] dos conceitos herdados por essa mesma tradição. Por outro lado, tomando distância em relação à radicalidade da recusa heideggeriana - que se evidencia, por exemplo, nos Cadernos Negros aproxima-se construtivamente dos momentos tradicionais do pensamento, os quais devem se tornar prolíficos para uma análise do ser e do vínculo a si próprio do humano no presente.

\section{II.2 Fink}

O próprio Fink considera o pensamento como o começo de uma nova época histórica, como o pensamento do mundo. Esse despertar do mundo, no entanto, corresponde a uma ênfase do humano que não compreende a "virada" [Kehre] de Heidegger mas, antes, apreende a duplicação da fenomenologia ontológica em ontologia existencial e pensamento do ser, 
ambos conectados em uma dialética contrastante. O humano é, no pensamento de Fink, o modelo de ser: o lugar onde a verdade do ser se desoculta. Ele é a "brecha metafísica no cosmos", o "governador" do absoluto, como Fink escreve em suas notas de trabalho (FINK, 2006, p.297). Por conseguinte, a ele é dada a possibilidade de aprimorar a famosa formulação "o humano é circunscritor do nada" (HEIDEGGER, 1976, p.118), da qual se serve Heidegger no seminário inaugural de 1929, publicado sob o título $O$ que é metafísica?, para resumir a ideia fundamental de uma comparação muito mais ampla e mais articulada com a metafísica, que ao mesmo tempo se destaca como a abertura de uma nova perspectiva de pensamento. Fink então escreve: "O humano é circunscritor do absoluto em sentido duplo: 1) ao invés do absoluto (portão de entrada), 2) ele suporta o absoluto em seu ser" (FINK, 2006, p.307).

Em meio à dependência que o filosofar de Eugen Fink apresenta em relação a Heidegger, mostra-se aqui, no contraste das interpretações antropológica e ontológica da técnica moderna, a distância todavia presente entre ambos. A técnica moderna, para Fink, implementa diretamente uma nova época ontológica, a saber, a época do fabricar. Justamente na forma verbal do "fabricar" [Herstellen], comparada ao substantivo "dispositivo" [Gestell], é já possível antever a especificidade do pensamento de Fink a respeito da técnica: a análise da técnica moderna é incorporada a uma fenomenologia do trabalho. Isso está, uma vez mais, assentado em uma antropologia existencial concebida de modo plural e que apresenta uma analítica do Dasein em sentido heideggeriano materialmente estendida. Mais além do pensamento de Heidegger, Fink enfatizou o aspecto da co-existência, cujo interesse e importância se revela na abertura de perspectivas filosóficas que nos ajudam a pensar a contemporaneidade e os problemas da realidade atual. Essa concepção antropológicosociológica total foi elaborada pela primeira vez no seminário do semestre de verão de 1955 , que tinha por tema os Fenômenos fundamentais da existência humana. Esse material foi postumamente publicado em 1979 sob o mesmo título.

A analítica do Dasein de Fink, a qual pretende analisar a situação humana no aqui e agora, parte de um entrelaçamento e de uma interconexão dialéticos entre os cinco fenômenos antropológicos fundamentais, todavia não reconduzíveis uns aos outros. Os cinco fenômenos fundamentais são Eros e a morte, o trabalho e a dominação e, por fim, o jogo. Os fenômenos fundamentais correspondem às dimensões igualmente fundamentais da finitude humana, nas quais o humano compreende seu ser e indica esse procedimento de modo igualmente compreensível. Eles representam o modo de ser e de compreender próprios da existência humana. Além disso, o humano cria aqueles momentos de compreensão para o mundo 
enquanto totalidade a partir de seus próprios procedimentos de ser, do jogo que se estabelece entre ser e nada. A diferença entre uma antropologia filosófica e uma interpretação científicopositiva do humano pode ser encontrada na "colocação entre parênteses do autoconhecimento humano e do problema do ser" (FINK, 1979, p.438).

No quadro dessa concepção antropológica global, a técnica moderna torna-se tema na análise do fenômeno fundamental "trabalho".

\begin{abstract}
$\mathrm{Na}$ época moderna, no desmoronamento da difundida ordem feudal e da interpretação supra-naturalística do mundo, o trabalho incide cada vez mais fortemente nos meios da vida humana e alcança, no mundo moderno e técnico, uma posição de prioridade tal, que os problemas existenciais surgem como problemas de trabalho e a imagem do homem parece representado na "figura do trabalhador" (FINK, 1979, p. 250).
\end{abstract}

O apelo, não casual, à “figura do trabalhador”, tal como presente nessa citação, abre interessantes conexões hermenêuticas sobre a questão da técnica, tal como elaborada por Fink e Heidegger, mas também em relação a outros dentre os grandes pensadores alemães: Ernst Jünger quem, em 1932, publica seu famoso ensaio O trabalhador. Dominação e Figura (JÜNGER, 2014) e Hannah Arendt que, tanto em sua obra Vita activa oder Vom tätigen Leben de 1958 (ARENDT, 2015) quanto no ensaio Über die Revolution de 1963 (ARENDT, 1994), mostra decididamente sua inconformidade com a concepção - assumida por Heidegger - que, na esteira de Platão, funda a dominação [Herrschaf] sobre a técnica. Arendt critica a comparação heideggeriana entre trabalho [Arbeit] e técnica, e justifica a distinção entre dominação e técnica a partir dessa diferenciação fundamental. Sobre isso, é bastante instigante o fato de que o marco da ontologia fundamental que Heidegger desenvolve em Ser e Tempo através da analítica existencial do Dasein, o modelo para a análise da "cotidianidade" (isto é, do modo como a vida se encontra imediata e regularmente no mundo) e da "mundaneidade" do mundo seja, essencialmente, o modelo do trabalho artesão do mundo camponês. Na obra capital de 1927 não há, notoriamente, nenhuma referência ao trabalho industrial em sentido moderno, tal como amplamente mencionado, por exemplo, nos escritos de Durkheim, Marx ou Weber. É somente por volta dos anos 30 que essa perspectiva começa a se modificar. Heidegger percebe que o que caracteriza essencialmente nossa época e, nela, a realização da vida humana, não é a cotidianidade rural [bäuerlich] mas, antes, o trabalho industrial e a técnica, tal como descrita por Ernst Jünger nos ensaios Die totale Mobilmachung de 1930 (JÜNGER, 2002) e o já citado $O$ trabalhador. A técnica no sentido jüngeriano é essencialmente o modo como a nova e epocal forma do trabalhador mobiliza o 
mundo. Sobre a base de vários estudos e contribuições historiográficas pode-se afirmar que a técnica se converte em uma temática central e decisiva da reflexão heideggeriana a partir de uma detalhada confrontação com a obra de Jünger.

Também para Fink, o trabalho fornece uma perspectiva global da existência humana. No entanto, na filosofia de Fink, o trabalho está dialeticamente vinculado aos demais fenômenos fundamentais que compõem a existência humana. $\mathrm{O}$ fundamento dinâmico do trabalho se revela na técnica moderna, através da qual Fink assinala o aspecto criador próprio ao que ele denomina "liberdade que projeta" [planender Freiheit], aspecto este no qual jaz o elemento 'titânico' do trabalho humano: não tanto o objeto fabricado mas, antes, o fabricar enquanto atividade central, enquanto produção das condições de possibilidade da produção.

Uma diferença conceitual em relação ao pensamento de Heidegger deixa-se observar na caracterização da socialidade humana como algo positivo. Os fenômenos fundamentais são basicamente estruturas sociais da existência humana. Segundo Fink, o caráter de co-existência do trabalho se deixa evidenciar na divisão do trabalho, uma vez que esta transforma o trabalho em uma atividade que necessariamente envolve os espaços público e social. Ninguém fabrica tudo sozinho; todos trabalham conjuntamente. Nas culturas primitivas o trabalho era, de início, trabalho manual. Era, portanto, considerado a partir de uma dimensão prática e vinculada ao uso do corpo: assim tiveram início as relações comunitárias na Antiguidade. O trabalho teórico foi posicionado acima do trabalho prático e este foi, mais recentemente, repassado aos serviçais. Nisso está fundamentada a prioridade do "ideal" diante do "real" na tradição ocidental, e isso não diz respeito apenas ao senhorio, agora desatarefado, mas igualmente aos filósofos e padres. É justamente o fenômeno da dominação que é colocado em questão pela divisão do trabalho, pois se o trabalho reflete o vínculo do homem aos seus talentos naturais, então a dominação reflete o vínculo do homem com o próprio homem. $\mathrm{O}$ trabalho surge da diferença entre o que é humano e o que é natureza, já a dominação surge da diferença entre aqueles homens que são subordinados e aqueles aos quais estes se subordinam. O íntimo entrelaçamento dos dois fenômenos fundamentais e não deriváveis entre si de "trabalho" e "dominação" torna-se particularmente visível no fato de que as categorias que dizem respeito a uma dimensão vital de um são convocadas para a análise do outro.

Enquanto Fink, em sua obra sobre os Fenômenos fundamentais da existência humana, ainda assume um equilíbrio entre a $\tau \dot{\varepsilon} \chi v \eta$ antiga e a técnica moderna, e isso mesmo para uma compreensão contemporânea do trabalho sob as condições de automação, o aspecto do 
estático desaparece completamente no seminário que Fink proferiu um ano depois, no semestre de verão de 1956, intitulado Problemas da filosofia social e publicado em 1974 com o título Tratado sobre o poder humano. Não mais uma tensão entre, por um lado, a satisfação das necessidades imperativas ligadas à natureza e, por outro, a liberdade histórica; ao invés disso, é tão-somente o fundamento dinâmico que se apresenta como aquilo que deve ser suportado. A demarcação do trabalho a partir de seus produtos se agrega a uma visão tanto humana quanto mundana que se caracteriza, principalmente, como estática, metafisicamente fundamentada e prematura. Na direção oposta, enfatiza-se o aspecto dinâmico-titânico da técnica moderna, o qual pertence pura e simplesmente à tarefa filosófica da atualidade, deflagrada através da dinâmica da modernidade e a ser determinada por categorias apropriadas a ela. Antes como agora, Fink emprega, para sua análise da humanidade moderna, conceitos e noções provenientes da metafísica onto-teológica, que ordenam hierarquicamente teoria e práxis, realidade e possibilidade, e que dá àquilo que permanece a prioridade em relação àquilo que está sempre em movimento. Os vínculos modernos da vida apontam, entretanto, para uma dissolução de todos os momentos estáticos. A revolução técnica segue permanentemente adiante e se alastra sobretudo pelo âmbito da política. As formas de dominação baseadas em metafísicas religiosas desvanecem. A religião é destituída em uma dimensão cujo direcionamento é antropológico. Seu lugar é usurpado pelo trabalhador da era da máquina, "vê-se o verdadeiro poder no fazer e, precisamente, num fazer interminável e ininterrupto. Apenas produtividade ainda vale como poder. Não aos produtos, é ao poder de produção que tudo diz respeito" (FINK, 1974, p.190).

A projeção da técnica é planetária. O modo de ser da produção é o fundamento tanto da técnica quanto da política. O fazer encarrega-se do poder. O poder político vem sendo cada vez mais tomado pelo trabalhador, e a dominação é dominação do trabalho. A dissolução de figuras estáticas vai de encontro às ordenações políticas. Do mesmo modo que a revolução técnica vai permanentemente adiante, também o faz a revolução política. Dominação, poder, consecução, tornam-se conceitos-guia de uma nova ontologia do movimento. A liberdade do homem moderno é, tanto na técnica quanto na política, uma liberdade produtora.

A transformação da existência humana que encontra na técnica moderna uma expressão documentária é, dentre todas, a mais essencial. Podemos indicar essa transformação como uma tentativa de existir e co-existir na efetivação criadora da vida, como o conformar de toda a existência humana para além da enigmática força produtora; e conformar de forma tal que essa força produtora não se esgote nos produtos temporários ou cessem por meio deles 
e que, sobre oscilações livres e a cada vez novas, estenda-se em uma inesgotabilidade infinita. O que se mostra para Fink nessa análise existencial da existência humana a partir dos fenômenos do trabalho e da dominação é, todavia, o problema ontológico par excellence. $\mathrm{O}$ estático de uma ontologia antecipada da substância não é mais adequado para compreender de modo categorial a dinâmica criadora da modernidade político-técnica da humanidade. A humanidade moderna cria a partir do nada. Não é por acaso que "o nada" tornou-se o valor fundamental do niilismo europeu que, por sua vez, mobiliza a corrupção da metafísica da substância. Mesmo a diferença entre técnica e política parece se dissolver aqui, pois Fink passa a fundar a técnica curiosamente sobre a política, e não o contrário. E isso acontece porque não só os produtos se liquefazem, mas igualmente o próprio homem, e mesmo que a dinâmica da técnica esteja muito mais avançada que o processo de dissolução dos ordenamentos estáticos da política, a política e a técnica modernas são questões da maior relevância ontológica. Na política e na técnica se revela uma ontologia do movimento, a qual deve ser ainda concebida conceitualmente. $\mathrm{O}$ perigo da reificação, submetido às coisas do homem fabricante, decompõe-se atualmente na auto-produção dinâmica, na qual o que conta não é mais o produto, mas as possibilidades criadoras da produção. Como afirma Fink (1974, p. 193): "a essência humana se estabelece em seu fabricar - e todo fabricar político e técnico assegura sobretudo o próprio seguimento do fabricar".

\section{Conclusão}

Tanto Heidegger quanto Fink veem a técnica moderna como um problema ontológico de mais alto nível. Para ambos os representantes da fenomenologia ontológica, é na questão da técnica que emerge uma nova ontologia, a qual não se deixa mais determinar pelas categorias da metafísica da substância. A humanidade se encontra agrilhoada nessa circunstância de um modo muito especial, ainda que Fink atribua ao homem, mais que Heidegger o fez, um caráter de modelo. A formulação da tarefa filosófica, tal como ela se projeta para ambos os pensadores, aponta para uma nova dimensão do pensar ontológico e fenomenológico. O desocultamento da verdade do ser não só pode ser esperada, mas deve ser também elaborada sobre o próprio modelo humano. Essa é a intenção que subjaz ao filosofar de Fink, o qual não apenas reinterpretou a fenomenológica como "filosofia do trabalho" num sentido husserliano, mas pensou igualmente a problemática relação ente técnica e liberdade 
sob uma perspectiva inovadora e particular, sobre o pano de fundo de um diálogo com Heidegger que superou a marca dos 50 anos.

\section{REFERÊNCIAS BIBLIOGRÁFICAS}

ARENDT, H. Vita activa oder Vom tätigen Leben, München - Zürich: Piper, 2015.

ARENDT, H. Über die Revolution. München - Zürich: Piper, 1994.

BRUZINA, R. Edmund Husserl \& Eugen Fink. Beginnings and Ends in Phenomenology. New Haven/London: Yale University Press, 2004.

CRISTIN, R. Phänomenologische Ontologie. Heideggers Auseinandersetzung mit Husserl (1916-1928). In: Heidegger-Jahrbuch. Freiburg, 6, 2012, 43- 68.

FINK, E. Sein, Wahrheit, Welt. Vor-Fragen zum Problem des Phänomen-Begriffs. Den Haag Nijhoff, 1958.

FINK, E. Studien zur Phänomenologie 1930-1939. Den Haag: Nijhoff, 1966.

FINK, E. Traktat über die Gewalt des Menschen. Frankfurt a. M.: Klostermann, 1974.

FINK, E. Grundphänomene des menschlichen Daseins. Freiburg/München: Karl Alber, 1979.

FINK, E. VI. Cartesianische Meditation. Teilband I: Die Idee einer transzendentalen Methodenlehre. Dordrecht: Springer, 1988a.

FINK, E. VI. Cartesianische Meditation. Teilband II: Ergänzungsband: Texte aus dem Nachlass Eugen Finks (1932) mit Anmerkungen und Beilagen aus dem Nachlass Edmund Husserls (1933/34). Dordrecht: Kluwer, 1988b.

FINK, E. Natur, Freiheit, Welt. Philosophie der Erziehung. Würzburg: Königshausen \& Neumann, 1992.

FINK, E. Phänomenologische Werkstatt 1 (Eugen Fink Gesamtausgabe 3/1). Freiburg/München: Karl Alber, 2006.

GIUBILATO, G.J. Sulle spalle dei giganti. Questioni di metodo. In: FINK, E. Presentificazione ed Immagine. Milano: Mimesis, 2014, 311-330.

GIUBILATO, G.J. El camino a la libertad. Eugen Fink y el principio de la fenomenología. In: Franciscanum, Bogotá, 167, 23-50.

GIUBILATO, G.J. Freiheit und reduktion. Grundzüge einer phänomenologischen Meontik bei Eugen Fink (1927-1946). Nordhausen: Bautz 2017b.

HEIDEGGER, M. Wegmarken. Frankfurt a. M., Klostermann: 1976.

HEIDEGGER, M. Vorträge und Aufsätze. Frankfurt a. M.: Klostermann, 2000.

HEIDEGGER, M. Überlegungen II-VI (Schwarze Hefte 1931-1938). Frankfurt a. M.: Klostermann, 2014a.

HEIDEGGER, M. Überlegungen VII-XI (Schwarze Hefte 1938/39). Frankfurt a. M.: Klostermann, 2014b.

HEIDEGGER, M. Überlegungen XII-XV (Schwarze Hefte 1939-1941). Frankfurt a. M.: Klostermann, 2014c. 
HEIDEGGER, M. Anmerkungen I-V (Schwarze Hefte 1942-1948). Frankfurt a. M.: Klostermann, 2015.

JÜNGER, E. Der Arbeiter: Herrschaft und Gestalt. Stuttgart: Klett-Cotta, 2014.

JÜNGER, E. A mobilização total, In: Natureza Humana 4(1): 189-216, São Paulo 2002

KANT, I. A religião nos limites da mera razão. Corvilhã: Universidade da Beira Interior, 2008.

LUFT, S. Phänomenologie der Phänomenologie. Systematik und Metodologie in der Auseinandersetzung zwischen Husserl und Fink. Dordrecht/Boston/London: Kluwer, 2002.

NANCY, J. L. Das nackte Denken. Zürich/Berlin: Diaphanes, 2014

NANCY, J.L. Banalité de Heidegger. Paris: Galilés, 2015.

NIETZSCHE, F. Werke in drei Bänden. Vol. 2. München: Hanser Verlag, 1954.

SEPP, H.R. Totalhorizont - Zeitspielraum. Übergänge in Husserl und Fink Bestimmung von Welt. In: BOEHMER, A. (Org.). Eugen Fink. Sozialphilolophie - Anthropologie Kosmologie - Pädagogik - Methodik. Würzburg: Königshausen \& Neumann, 2006.

SEUBOLD, G. Heideggers Analyse der neuzeitlichen Technik. Freiburg/München: Karl Alber, 1986.

TRAWNY, P. Finks 'Lebenslehre'. In: HILT, A., NIELSEN, C. (Org.). Bildung im technischen Zeitalter. Sein, Mensch und Welt nach Eugen Fink. Freiburg/München: Alber, 2005, 342-362.

TRAWNY, P. Technik, Kapital, Medium. Das Universale und die Freiheit. Berlin: Matthes \& Seitz, 2015.

VAN KERCKHOVEN, G. Mundanisierung und Individuation. Die VI Cartesianische Meditation und ihr Einsatz. Würzburg: Königshausen \& Neumann, 2003. 